REVISTA X, Curitiba, volume 14, n.4,p. 300-321, 2019

\title{
EXCLUSÃO DAS PESSOAS CEGAS: DA ELIMINAÇÃO NAS SOCIEDADES ANTIGAS À HOSTILIZAÇÃO NAS UNIVERSIDẢDES ATUAIS, O QUE MUDOU? ${ }^{1}$
}

Exclusion of Blind People: from elimination in old societies to their hostilization in current universities, what has changed?

\author{
Simone de Fátima Colman MARTINS - UFPR ${ }^{2}$ \\ Francisco Calvo del OLMO - UFPR ${ }^{3}$
}

\begin{abstract}
RESUMO: O presente trabalho é resultado parcial de uma pesquisa de doutorado em andamento. A pesquisa visa investigar as crenças de avaliar as produções textuais manifestadas por estudantes cegos ou com baixa visão da APADEVI/PG ${ }^{4}$ (Associação de Pais e Amigos do Deficiente Visual em Ponta Grossa). Dos nove estudantes-participantes, cinco cursam uma graduação e quatro participaram dos vestibulares locais no ano de 2018, seis deles são cegos e três têm baixa visão. Metodologicamente, a pesquisa é qualitativa e os dados advêm de dois instrumentos: entrevistas de grupo focal e entrevistas individuais semiestruturadas. Neste artigo, apresentamos uma análise do processo histórico da pessoa cega destacando as experiências vivenciadas pelos estudantes nos ambientes universitários. Como resultados observamos que o processo avaliativo acadêmico envolvendo alunos cegos/baixa visão é extremamente complexo, ele abrange necessariamente questões de respeito, aceitação e sensibilidade dos envolvidos, pressupõe também a administração de inúmeros confrontos. Os estudantes revelaram suas realizações quando cumprem as atividades exigidas e suas angústias quando são desmotivados com críticas negativas, apontados como incapazes, diferentes/inferiores ou tratados com indiferença.
\end{abstract}

PALAVRAS-CHAVE: inclusão; cegueira e baixa visão; avaliações acadêmicas.

\begin{abstract}
The present work is part of an doctoral research in development. The research aims to investigate the beliefs of evaluating the textual productions manifested for of students blind or low vision of APADEVI/PG (Association of Parents and Friends of the Visual Impairment in Ponta Grossa). Of the nine students-participants, five attend a graduation and four did the local entrance
\end{abstract}

\footnotetext{
${ }^{1}$ Este artigo é resultado parcial de uma pesquisa de doutorado do Programa de Pós-Graduação em Estudos Linguísticos da Universidade Federal do Paraná e foi realizado com apoio da Coordenação de Aperfeiçoamento de Pessoal de Nível Superior - Brasil (CAPES) - Código de Financiamento 001 Portaria $\mathrm{n}^{\circ}$ 206, de 4 de setembro de 2018. A pesquisa insere-se no projeto Interfaces da Intercompreensão em Línguas Românicas e a promoção do Plurilinguismo sob a orientação do Prof. Dr. Francisco Calvo del Olmo, bolsista do Programa de Cooperação França-Brasil CAPES-COFECUB.

2 Doutoranda e bolsista (CAPES) em Estudos Linguísticos no Programa de Pós-Graduação da Universidade Federal do Paraná (UFPR).

3 Doutor em Estudos da Tradução pela Universidade Federal de Santa Catarina-UFSC; Professor Adjunto no Departamento de Letras Estrangeiras Modernas da Universidade Federal do Paraná (UFPR).

${ }^{4}$ Para saber mais informações sobre a APADEVI/PG (Associação de Pais e Amigos do Deficiente Visual/PG) visitar o site http://apadevipg.wix.com/apadevi ou a página www.facebook.com/apadevi.pontagrossa
} 
exams in the year 2018, six of them are blind and three have low vision. Methodologically, the research is qualitative and the data come from two instruments: focus group interviews and semi-structured individual interviews. In this article we present a brief analysis of the historical process of the blind person highlighting the experiences lived by these students in university environments. As results, we observe that the academic evaluation process involving students blind/low vision is extremely complex, it necessarily involves questions of respect, acceptance and sensitivity of the involved, it also presupposes the administration of numerous confrontations. Students have revealed their accomplishments when they fulfill the required activities and theirs afflictions when they are discouraged by negative criticisms, pointed out as incapable, different/inferior, or when they are treated with indifference.

KEYWORDS: inclusion; blindness and low vision; academic evaluations.

\section{DIRECIONANDO O OLHAR}

Cursar algumas disciplinas do Programa de Pós-Graduação da Universidade Federal do Paraná no ano de 2018 nos proporcionou o contato com inúmeros autores que discutem concepções de língua(gem) ${ }^{5}$, políticas e ideologias linguísticas em contextos educacionais pluri/multilíngues e pluri/multiculturais; ou seja, contextos bastante complexos, nos quais os contatos linguísticos, bem como as políticas e ideologias linguísticas, influenciam e ao mesmo tempo são influenciados pelas relações, pelos sujeitos, pelas ações e pelos fatos.

César e Cavalcanti (2007, p. 47) explicam a importância de "abordar o conceito de língua em função das necessidades e dilemas que enfrentamos na pesquisa e no trabalho pedagógico com a língua(gem)" pois precisamos (re)fazer uma leitura crítica de categorias tidas como básicas. Ainda de acordo com os autores, esta reflexão torna-se extremamente urgente quando pesquisamos contextos específicos como podem ser o das chamadas "minorias linguísticas" (CÉSAR; CAVALCANTI, 2007, p. 47).

Com relação ao termo minoria, Olmo (2014, p. 42) problematiza algumas definições originárias de vários campos das Ciências Humanas e Sociais. Entre as explicações, o autor destaca a da antropóloga Françoise Héritier (apud OLMO, 2014, p. 42, tradução nossa) que mostra a necessidade de dissociar o termo da relação numérica entre duas comunidades e vincula o conceito às relações de hierarquia entre grupos humanos; por sua vez, a psicóloga Betty Goguikian Ratclif (apud OLMO, 2014, p. 42, tradução nossa) afirma que "pertencer a uma minoria implica as noções de diferença,

\footnotetext{
${ }^{5}$ No decorrer do texto usaremos a expressão língua(gem) - língua/linguagem - por entendermos como termos inseparáveis e ao mesmo tempo complementares.
} 
alteridade, desvio social e diferença a respeito da norma"; (apud OLMO, 2014, p. 43, tradução nossa) explica que "uma minoria é uma população que se representa a si mesma como diferente do conjunto da população de um país, ou que é enxergada assim pela maioria" ". Já o sociólogo Éric Fassin (apud OLMO, 2014, p. 43-44, tradução nossa) ressalta as relações de poder entre grupos distintos e "a minoria não está definida pelo número, mas pela dominação que a minimiza ${ }^{8}$ "; por fim, a explicação do campo da linguística, de Jeroen Darquennes (apud OLMO, 2014, p. 43, tradução nossa) indica que as diferenças estruturais inter/intralinguísticas não são suficientes para definir minorias linguísticas e "essas múltiplas diferenças praticamente impossibilitam a busca de uma definição universal do conceito de minoria linguística ${ }^{9}$ ". Todas essas definições nos ajudam a recortar nosso objeto de pesquisa.

Nesse sentido, entendemos que os alunos cegos presentes nas escolas regulares, nos processos seletivos e nas universidades fazem parte destas "minorias linguísticas", pois o uso do braile ${ }^{10}$, a necessidade constante de descrições orais ${ }^{11}$ e a presença de leitor/transcritor nos processos avaliativos representam um contexto extremamente particular. Chamam nossa atenção as ideologias/concepções de língua(gem) que permeiam todo o ambiente acadêmico, onde "o diferente" não é entendido em sua complexidade, muito menos acolhido de forma respeitosa (MAHER, 2007, p. 68); o que acontece em alguns casos é a hostilidade e a indiferença em relação a esses alunos. Então, concordamos com Cardoso (2003) e Maher (2007) ao reforçarem que o "respeito à diversidade não pode ficar no plano do jargão politicamente correto: é fundamental agirmos, de maneira informada, para garantir o seu pleno exercício" (MAHER, 2007, p. 68). Dessa forma, um dos papéis do professor atual é encarar os "desafios de um mundo

\footnotetext{
${ }^{6}$ Do original: pertenecer a una minoría implica las nociones de diferencia, alteridad, desviación social y diferencia con respecto a la norma.

7 Do original: una minoría es una población que se representa a sí misma como diferente al conjunto de la población de un país, o que es vista como tal por la mayoría.

8 Do original: la minoría no está definida por el número, sino por la dominación que la minimiza.

9 Do original: estas múltiples diferencias prácticamente imposibilitan la búsqueda de una definición universal del concepto de minoría linguística.

${ }^{10}$ Sistema Braille - Processo de leitura em relevo baseada no código militar denominado "escrita noturna". Inventado em 1829, por Louis Braille, consiste num sistema de seis pontos em relevo, dispostos verticalmente em duas filas de três pontos cada. Os seis pontos formam sessenta e três combinações diferentes, as quais representam o alfabeto, números, sinais de pontuação, símbolos matemáticos, químicos, físicos e notas musicais (FRANCO e DIAS, 2005, p.3).

${ }^{11}$ Dantas (2014) destaca a importância da linguagem para o desenvolvimento da pessoa cega pois a linguagem é ao mesmo tempo signo e olho. Por isso ressaltamos que no trabalho com alunos cegos há a necessidade de realizar descrições do que acontece a sua volta, as ações, as imagens, os objetos... As descrições podem ser feitas por pessoas, através da escrita em braile ou por programas de leitores de tela.
} 
REVISTA X, Curitiba, volume 14, n.4,p. 300-321, 2019

onde comunidades plurais precisam lutar para serem visibilizadas e aceitas" (MAHER, 2007, p. 68), com isso não defendemos que esta tarefa corresponde apenas ao professor, muito pelo contrário, reforçamos a necessidade de toda a sociedade promover a inclusão, não apenas aceitá-la, mas transpor as barreiras que excluem aqueles que não correspondem ao padrão socialmente estabelecido .

Por isso, o objetivo deste artigo é (re)pensar e questionar o contexto vivenciado por jovens universitários cegos ou com baixa visão que frequentam cursos de graduação em Instituições de Ensino Superior na cidade de Ponta Grossa-PR. Enfatizamos que esta análise insere-se numa pesquisa de Doutorado do Programa de Pós-Graduação da Universidade Federal do Paraná (UFPR) e encontra-se em sua fase inicial. Por tratar-se de um estudo qualitativo, apresentamos informações sobre a legislação inclusiva, o histórico sobre o tratamento da sociedade em relação à pessoa cega, descrições detalhadas sobre os encontros de grupo focal e características dos estudantesparticipantes com o intuito de revelar o contexto no qual o estudo acontece.

Informamos que a pesquisa foi aprovada pelo Comitê de Ética em Pesquisa por envolver o trabalho com seres humanos e a aprovação pode ser verificada no Parecer Consubstanciado $\mathrm{n}^{\mathrm{O}}$. 2.754.433.

\section{OBSERVANDO A LEGISLAÇÃO INCLUSIVA}

Ao analisarmos o contexto brasileiro, apontamos como marco inicial das ações oficiais do poder público sobre a educação especial o artigo 88 da Lei de Diretrizes e Bases da Educação Nacional - LDBEN de 1961, Lei 4.024/61 que estabelece "[...] a educação de excepcionais deve, no que for possível, enquadrar-se no sistema geral de educação". Dez anos depois, em 1971, a LDBEN foi alterada e o documento reforça que as crianças com necessidades especiais devem estudar apenas em instituições especializadas, retrocedendo, assim ao que foi proposto em 1961. Entretanto, a partir da Constituição Federal de 1988, estabeleceu-se um ensino com o objetivo de promover "a igualdade de condições de acesso e permanência na escola" para todos, sem nenhum tipo de preconceito e a Lei 7.853 de 24 de outubro de 1989, mais conhecida como a Lei da Inclusão, aponta como crime a recusa de algum aluno nas escolas regulares, reforçada pelo Estatuto da Criança e do Adolescente em 1990 que prevê a obrigação dos pais e/ou responsáveis de matricular seus filhos na rede regular de ensino.

De certa forma, a década de 90 pode ser considerada um período de grandes avanços pois os "documentos e fóruns internacionais passam a influenciar a formulação 
das políticas educacionais" (DANTAS, 2014, p. 36), entre os mais importantes citamos a Conferência Mundial de Educação para Todos (1990), a Declaração de Salamanca (1994), a Convenção da Guatemala (1999), a Resolução CNE/CP n ${ }^{0}$. 1/2002 que estabelece as Diretrizes Curriculares Nacionais para a Formação de Professores da Educação Básica, a divulgação do Plano de Desenvolvimento da Educação em 2007, o Decreto $\mathrm{n}^{0}$. 6.094, que estabelece as Diretrizes do Compromisso de Todos pela Educação e o Plano Nacional de Educação (PNE) em 2010.

E uma das conquistas alcançadas através da legislação foi a presença desses alunos nos ambientes acadêmicos, pois ao frequentarem as escolas regulares passaram a participar dos processos de vestibular, do ENEM $^{12}$ e, apesar de nem todas as universidades reservarem vagas $\mathrm{PcD}^{13}$, muitos conseguiram ingressar em cursos de graduação. Por um lado, percebemos o aumento de alunos com diversidade funcional ${ }^{14}$ que chegam nos cursos superiores em universidades brasileiras, por outro lado, o número ainda limitado de pesquisas, reflexões e discussões sobre o assunto, fazem da questão um grande desafio, o qual precisa ser percebido, (re)visto e questionado.

O último Censo de Educação Especial no Ensino Superior no Brasil foi realizado em 2008; ele registra um aumento de $136 \%$ de alunos com diversidade funcional que ingressaram em cursos superiores entre os anos 2003 e 2005, de 5.078 alunos em 2003 passou para 11.099 em 2005 e quando nos voltamos para os alunos cegos ou com baixa visão, observamos um crescimento ainda maior, de 920 alunos em 2003 para 3.418 alunos em 2005, um aumento de 237\%. Esses dados servem como argumento para atentar sobre a necessidade de propiciar e praticar no dia a dia a inclusão nas universidades. Sobre a questão, Magalhães (2013, p. 49) nos explica que a inserção de alunos com diversidades funcionais no nível superior de ensino "está ocorrendo de forma lenta e ainda sem mecanismos que sustentem tanto o acesso, quanto a permanência de tal aluno no contexto das exigências peculiares à educação superior". A autora enfatiza que a garantia de vagas não é suficiente, as universidades devem

\footnotetext{
12 Exame Nacional do Ensino Médio. Em algumas universidades, em vez de prestar o vestibular, o candidato entra na universidade por meio do SISU (Sistema de Seleção Unificado) com a nota do ENEM.

${ }^{13}$ A Lei n. ${ }^{\circ} 12.711 / 2012$ alterada pela Lei $n^{\circ}$ 13.409/2016 prevê vagas destinadas às Pessoas com necessidades Especiais.

14 O termo "diversidade funcional" foi apresentado por Javier Romanach e Manuel Lobato em maio de 2005, no Foro de Vida Independiente. Eles utilizam inclusive a forma abreviada PDF (Pessoa com Diversidade Funcional do original Persona con Diversidad Funcional). Os autores explicam a necessidade de se utilizar um termo que propõe a dignidade das pessoas e não termos médicos que reforçam e inferiorizam uma pessoa em relação à outra.
} 
organizar estratégias que colaborem com o sucesso escolar destes alunos. Ademais, percebemos que as leis estabelecem a inclusão com seus artigos, incisos e alíneas; porém, as realidades acabam impondo a exclusão com a indiferença, a hostilidade, a falta de acesso e a imposição de obstáculos intransponíveis, como alguns processos avaliativos acadêmicos.

Dedicamos a seguinte seção para apresentar um breve resumo sobre o percurso histórico de como a sociedade em geral vem percebendo as pessoas cegas.

\section{Espiando o passado}

Franco e Dias (2005) explicam que, ao longo da história, as mudanças de atitudes em relação às pessoas cegas ocorreram em função da organização e das transformações da sociedade. Na Antiguidade, havia dois tipos de tratamento com as pessoas que não correspondiam às exigências do meio, ou eram tratadas com tolerância e apoio ou com menosprezo e eliminação, o que de certa forma permanece até os dias atuais. Como um exemplo, citamos fatos que ocorriam na cidade de Esparta, as crianças que nasciam fora do padrão físico estabelecido eram abandonadas ou eliminadas, era o procedimento mais comum. Algumas sociedades acreditavam que os cegos eram possuídos por espíritos maus e a cegueira era uma desgraça, crença existente até hoje. A seguir lemos um trecho escrito por José Álvares de Azevedo ${ }^{15}$ que revela uma das leis antigas da cidade de Esparta:

Vamos fallar da Grécia; do paiz das sciencias, das artes, da industria, do commercio; do paiz o mais civilisado das remotas eras, e em que o povo era tido em conta de muito humano. Dirijamo-nos para Spartha; abramos um seu livro celebre: o codigo de Licurgo. Que lemos nelle? Qual era a legislação dessa rival de Athenas? - Que todos os que, por algum defeito, não podiam ser uteis á patria, fossem, apenas nascidos, afogados no Eurotasso (AZEVEDO, 1851, p. 3).

É visível a ironia presente no trecho, pois ao se referir à Grécia, o país das ciências, do povo mais civilizado, o autor mostra uma lei severa de que "aqueles que

\footnotetext{
${ }^{15}$ José Álvares de Azevedo foi o primeiro professor cego brasileiro, responsável pela introdução do Braille no Brasil e considerado o "Patrono da educação de cegos no Brasil". Nasceu cego em 1834 e em 1844, com 10 anos, seus pais o enviaram à França, para o Instituto Real de Meninos Cegos de Paris. Lá ele aprendeu a ler e a escrever em braile e em 1850 retornou ao Brasil e transferiu seus ensinamentos para outras pessoas cegas. Traduziu o livro "O Instituto dos meninos cegos de Paris: sua história, e seu método de ensino por J. Guadet”. Foi idealizador do Imperial Instituto dos Meninos Cegos no Rio de Janeiro, hoje Instituto Benjamin Constant. Faleceu aos vinte anos, vítima de uma tuberculose, seis meses antes da inauguração do Instituto. Fonte: Instituto Benjamin Constant. http://www.ibc.gov.br/fique-pordentro/677-alvares-de-azevedo-o-disseminador-no-brasil.
} 
nascessem com algum defeito e que não fossem úteis para a pátria” (AZEVEDO, 1851) deveriam ser afogados no rio Eurotasso, que ficava às margens da cidade de Esparta. Num primeiro momento podemos observar esta lei como absurda, covarde e impossível de acontecer na atualidade, mas veremos o quanto alguns processos avaliativos continuam extremamente severos.

Durante a Idade Média na Europa, a cegueira foi usada como castigo ou vingança. Mecloy (1974) relatou que no século XI, os imperadores e reis vencedores das guerras davam ordens para arrancarem os olhos dos soldados prisioneiros/vencidos. Também nesse período, a cegueira era aplicada como pena judicial para crimes contra a divindade ou faltas graves às leis matrimoniais.

De acordo com Franco e Dias (2005) com o fortalecimento do Cristianismo, a condição dessas pessoas foi alterada, elas eram vistas com valor absoluto, afinal, todos eram considerados filhos de Deus e a cegueira passou a ser interpretada como uma maneira de ganhar o céu. Segundo Pessotti (1984) os cegos eram confinados, o asilo garantia o teto e a alimentação; mas, por outro lado, eram isolados e escondidos por serem considerados inúteis e incômodos.

Ainda de acordo com Franco e Dias (2005), a situação se modificou com o advento do mercantilismo e do capitalismo comercial. Nesse sentido, o Renascimento pode ser considerado um marco importante, pois foi um período em que preconceitos, normas, estatutos, crenças e práticas em relação às pessoas com diversidades funcionais foram revistas. A partir do século XVIII, o entendimento sobre a cegueira passou a ser mais aprofundado, o avanço na medicina também oportunizou atendimento especializado a essas pessoas. Em 1784, Valentin Haüy inaugurou na França, o Instituto Real dos Jovens Cegos de Paris ${ }^{16}$, a primeira escola do mundo destinada à educação de pessoas cegas e, em 1829, Louis Braille, aluno desta instituição, inventou o sistema de leitura em alto relevo: o Sistema Braille. Após a criação do instituto, começaram a surgir pesquisas sobre a cegueira. Um dos estudiosos que abordou a questão foi Vigotski (1994), segundo o autor, o cego congênito ${ }^{17}$ não sente a cegueira como deficiência, mas sim as consequências sociais acarretadas por essa falta de visão, uma vez que a ausência de tal órgão "[...] cria dificuldades quando a criança cega começa a

\footnotetext{
16 Institut Royal des Jeunes Aveugles de Paris.

${ }^{17}$ De acordo com Dantas (2014, p.170) cego congênito é aquele que nasce cego e não teve nenhuma experiência visual. Quando a perda da visão ocorre a partir da infância é concebida como cegueira adventícia ou adquirida.
} 
interagir socialmente" (VIGOTSKI, 1994, p. 5), assim, a cegueira é reconhecida quando acontece o contato social.

No percurso histórico, foi só “depois da Segunda Guerra Mundial e com a Declaração Universal dos Direitos Humanos, que se passou a pensar na possibilidade de atendimento à pessoa cega na escola regular" (FRANCO; DIAS, 2005, p. 4). De acordo com Santos (1995, p. 24), "até os anos 80 a integração desenvolveu-se dentro de um contexto histórico em que pesaram questões como igualdade e direito de oportunidades". Em 1981, a Organização das Nações Unidas (ONU) instituiu o Ano e a Década da Pessoa Portadora de Deficiência. Após a realização da Conferência Mundial de Educação para Todos(1990) e a Declaração de Salamanca de Princípios, Política e Prática para as Necessidades Educativas Especiais (1994), passou a vigorar a "era da

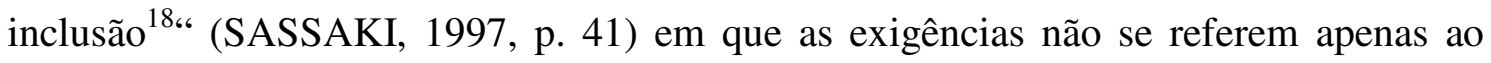
direito da pessoa com diversidade funcional à integração social, mas principalmente, ao dever da sociedade, como um todo, de se adaptar às diferenças individuais (BRASIL, 1994). E é este o ponto que pretendemos reforçar: o dever da sociedade se adaptar às diferenças individuais, não apenas nas leis e decretos, mas no dia a dia, nos mais variados ambientes sociais e educacionais.

A falta da visão, portanto, não pode ser entendida como impedimento para que o indivíduo cego se desenvolva, estude, trabalhe. Torna-se sim um conflito a situação gerada no contato social, "em que aquele que não é vidente é qualificado como o diferente, muitas vezes, também, como coitado e incapaz" (MEDRADO; DANTAS, 2014, p. 237).

Ao observarmos este contexto histórico, surge um questionamento: será que a situação mudou? Talvez, o início de pesquisas, a criação de instituições especializadas, as conferências mundiais, a alteração e o surgimento de leis que estabelecem o direito de pessoas cegas à integração social tenham sido os primeiros passos para uma mudança; porém, não conseguimos perceber tantos avanços quando conhecemos realidades que dificultam e impedem o crescimento/desenvolvimento desses alunos, quando percebemos que o senso comum denomina a cegueira como uma tragédia, fazendo “com que a comunicação e a relação com as pessoas cegas seja recheada de estereótipos e piedade" (BIGLIA, 2012, p. 53).

\footnotetext{
${ }^{18}$ De acordo com o autor o termo inclusão refere-se "ao processo pelo qual a sociedade se adapta para poder incluir, em seus sistemas sociais gerais, pessoas com necessidades especiais e, simultaneamente, estas se preparam para assumir seu lugar na sociedade" (SASSAKI, 1997, p. 41).
} 
Reconhecemos que, apesar da existência de leis de inclusão, o que presenciamos diariamente é que as minorias (no caso, os estudantes cegos/baixa visão) continuam sendo excluídos, ou seja, as leis por si não promovem a inclusão e muitos jovens com diversidades funcionais continuam sendo "afogados" não nos rios como explica Azevedo (1851), mas nos processos avaliativos em inúmeras universidades do país, quando são barrados pelos processos de seleção, quando suas avaliações diferenciadas são esquecidas ou quando não são percebidos em sala de aula. Assim, questionamos: até que ponto a sociedade e a situação dessas pessoas mudaram?

\section{RECONHECENDO O CAMINHO: METODOLOGIA}

No contexto da cegueira, apontamos a importância da pista tátil ${ }^{19} \mathrm{em}$ um passeio ou simplesmente para sair de casa. Infelizmente, na maioria dos lugares e caminhos ela não existe e verificamos a primeira barreira: a falta de acessibilidade; antes mesmo de iniciar a viagem já se enfrenta um enorme obstáculo. A pista deveria levar ao destino, mas a inexistência dela pode impedir de começar a viagem. Dessa forma, pretendemos abordar neste artigo um recorte, apenas um passeio, ou seja, como o jovem cego ou com baixa visão percebe os processos avaliativos nos cursos de graduação.

Esclarecemos que a viagem mais longa, isto é, a pesquisa mais ampla, do Doutorado é qualitativa, se insere dentro do quadro teórico da Linguística Aplicada (LA) e pretende produzir descrições detalhadas das situações, bem como de seus contextos. Para isso, organizamos dez encontros de grupo focal e entrevistas individuais semiestruturadas com os estudantes da APADEVI/PG que concordaram com a proposta. Reforçamos que nosso objetivo não é encontrar ou levar soluções para os questionamentos dos participantes, mas sim aprender e construir significações com aqueles que convivem diariamente e diretamente com a realidade acadêmica. O que importa é a possibilidade de diálogo e crescimento conjunto, por isso a ideia é "apostar nesse percurso nômade como estímulo ao desejo de curiosidade e criação, de pensar o impensado e de, apoiando-se no conhecido, torná-lo outro e estranhá-lo, para ousar ultrapassá-lo" (FABRÍCIO, 2006, p. 61). Nesse sentido, pretendemos "focalizar a

\footnotetext{
${ }^{19}$ De acordo com a NBR 9050 (Norma Brasileira), pista tátil é o piso caracterizado por textura e cor contrastantes em relação ao piso adjacente, destinado a constituir alerta ou linha-guia, servindo de orientação, principalmente, às pessoas cegas ou com baixa visão. São de dois tipos: piso tátil de alerta e piso tátil direcional. Ela mostra onde há um obstáculo, indica os caminhos e acesso a prédios, orienta a parada obrigatória antes de semáforos ou ruas, também pode receber o nome de caminho-guia, linha-guia ou simplesmente guia.
} 
REVISTA X, Curitiba, volume 14, n.4,p. 300-321, 2019

linguagem como prática social e observá-la em uso, imbricada em ampla amalgamação de fatores contextuais" (FABRÍCIO, 2006, p. 48) pois entendemos que ela é inseparável das práticas sociais e discursivas.

Antes de iniciarmos a pesquisa, visitamos a APADEVI/PG para comunicarmos a intenção de realizar um estudo com os universitários que frequentam a instituição. Neste primeiro contato, descobrimos que cinco estudantes se encaixavam nesse perfil, entretanto, a coordenadora nos passou os nomes de mais quatro jovens que tinham interesse em cursar uma graduação. Como cada aluno tem seus horários individuais, consideramos oportuno convidá-los para trocarem experiências, tirarem dúvidas e conhecerem mais o universo acadêmico.

Diante do fato, ficamos em dúvida se trabalharíamos com os estudantes do Ensino Médio também. Por tratar-se de uma pesquisa envolvendo a inclusão, não devíamos deixá-los de lado, seria uma contradição do intuito da própria pesquisa e por isso decidimos convidá-los. Após este contato inicial, combinamos um dia para expor os objetivos da pesquisa e fazer o convite individual aos alunos para participarem do estudo. A coordenadora solicitou que encaminhássemos um pedido formal ao presidente da APADEVI.

Assim, com os documentos organizados e cedidos pelo Comitê de Ética em Pesquisa da Universidade Federal do Paraná, encaminhamos o pedido ao presidente que autorizou a pesquisa e na sequência, comparecemos mais duas vezes na instituição, entre os meses de fevereiro e março de 2018, para conversarmos com os estudantes. Nesta etapa, foi interessante perceber a rápida aceitação por parte dos alunos em participar, todos se mostraram disponíveis e três deles, durante a conversa perguntaram quando seriam as reuniões.

Igualmente, organizamos as datas dos encontros e informamos a APADEVI. Até o momento em que escrevemos estas páginas, os encontros e entrevistas foram realizados nas dependências da instituição com uma duração aproximada de uma hora e trinta minutos. As interações estão sendo documentadas em áudio; após a gravação, os comentários são transcritos e fazem parte de um arquivo que poderá ser consultado no decorrer e andamento de toda a pesquisa. Realizamos seis dos dez encontros e oito das nove entrevistas individuais. A seguir apontamos de maneira resumida as atividades realizadas em cada um dos encontros:

$1^{0}$. Encontro: realizado no dia 19 de abril de 2018, contou com a participação de seis estudantes. Neste encontro a pesquisadora se apresentou, realizou o convite formal, 
fez a leitura dos termos de aceitação da pesquisa e esclareceu que os encontros e as entrevistas individuais seriam gravados e que todas as discussões serviriam de material para a realização da pesquisa de doutorado. Todos os presentes aceitaram participar. Na sequência, a pesquisadora mostrou uma gravação de áudio na qual o professor orientador se apresentou aos alunos e comentou sobre a pesquisa ${ }^{20}$. Em seguida, cada aluno fez uma apresentação pessoal, e contou o curso de graduação que frequenta, ou que pretende cursar, no caso dos alunos do Ensino Médio.

$2^{0}$. Encontro: realizado no dia 24 de maio de 2018, contou com a participação de cinco estudantes. Devido a paralisação dos transportes coletivos os demais não conseguiram se locomover até a instituição. No encontro foram resolvidas algumas questões burocráticas como por exemplo a organização e assinatura dos documentos que autorizam a realização da pesquisa e discutidas as formas como eles gostariam de receber a documentação. Imaginamos que eles iriam exigir em braile, no entanto, todos optaram pela assinatura em tinta e pediram para receber os documentos em seus e-mails no formato PDF ou Word para que pudessem ter acesso em seus computadores e consultarem se necessário.

$3^{\circ}$. e $4^{\circ}$. Encontros: realizados nos dias 21 de junho de 2018 com a participação de seis estudantes e no dia 16 de agosto com a presença de oito estudantes. Nestes encontros os participantes relataram experiências vividas no ambiente acadêmico/escolar, falaram sobre suas realizações (quando cumprem as atividades e são respeitados em suas diferenças) e angústias (quando são desmotivados com críticasnegativas, vistos como incapazes, diferentes, inferiores, tratados com indiferença e desconfiança). Comentaram também as experiências deles com as avaliações escritas que realizam no ambiente acadêmico.

$5^{\circ}$. Encontro: realizado no dia 27 de setembro de 2018, com a presença de oito participantes. Foram organizadas as datas para as entrevistas individuais semiestruturadas. As mesmas foram agendadas na própria APADEVI em dias e horários sugeridos pelos estudantes. O objetivo foi interferir o mínimo possível na rotina de cada um deles, alguns escolheram o dia que já estão na instituição, outros escolheram o dia com menos compromissos da graduação e assim por diante. Neste encontro os alunos criaram um grupo de whatsapp, realizaram comentários e relatos sobre a reação das

\footnotetext{
${ }^{20}$ Não foi possível a presença do Orientador pois o mesmo se encontra em período de estudos no Estágio Pós-Doutoral em Grenoble, França, na Universidade Grenoble-Alpes.
} 
pessoas quando os percebem fazendo atividades comuns como estudar, usar o celular, fazer compras, comer, pegar o ônibus.

$6^{\circ}$. Encontro: realizado no dia 25 de outubro de 2018, com a presença de oito participantes. A discussão aconteceu em torno da escolha dos temas de TCC (Trabalho de Conclusão de Curso) dos universitários, a participação dos jovens do Ensino Médio aconteceu no sentido de esclareceram dúvidas em relação ao trabalho e aos temas apresentados. Discutiu-se o cancelamento do encontro de novembro devido aos inúmeros compromissos acadêmicos do final do semestre e o próximo encontro foi combinado para fevereiro de 2019, a confirmação da data aconteceu através do grupo do whatsapp.

Destacamos que estudantes-participantes deste trabalho não serão, em hipótese alguma, tratados como meros informantes; isto é, a participação efetiva deles quanto dos demais responsáveis pela instituição implica uma responsabilidade ética de nossa parte em trazer a todo o momento um retorno, um sentido para o que se está fazendo (RAJAGOPALAN, 2003). Por isso nós, pesquisadores, os reconhecemos como participantes-pesquisadores ${ }^{21}$ e disponibilizamos uma breve apresentação revelando um pouco o perfil de cada um e de cada uma.

Participante-pesquisadora 1: tem 24 anos, cursa o sexto período de Educação Física numa IES (Instituição de Ensino Superior) particular. Com o diagnóstico Retinose Pigmentar, esta jovem possui uma porcentagem mínima de visão periférica, muito restrita, por isso, a identificamos com cegueira, ela utiliza a bengala para se locomover, faz uso do braile em escrita se necessário e em leitura com restrições. Realiza leituras através de leitores de tela ou através da escuta de leitura oral feita por outras pessoas, faz as avaliações do curso no computador e/ou oralmente com leitores e transcritores quando as avaliações exigem muitos desenhos.

Participante-pesquisador 2: tem 21 anos, cursa o sexto período de Jornalismo em IES particular e atualmente trabalha como estagiário na Câmara Municipal de Ponta Grossa, no departamento de Assessoria de Imprensa. Com cegueira congênita, utiliza a bengala para se locomover, faz uso do braile desde a infância tanto na escrita como na leitura. Realiza leituras através de leitores de tela, recebe as avaliações do curso em pen-

\footnotetext{
${ }^{21}$ Há pesquisas que entendem os participantes como informantes, nós pretendemos utilizar o termo participantes-pesquisadores pois os reconhecemos como essenciais para a pesquisa cuja participação e depoimentos tornam o estudo possível e encaminham o andamento da mesma.
} 
REVISTA X, Curitiba, volume 14, n.4,p. 300-321, 2019

drive e resolve com o auxílio do computador através de programas de leitura de tela, não precisa do auxílio de monitores, leitores ou transcritores.

Participante-pesquisadora 3: tem 20 anos, cursa o segundo período de Produção Publicitária em IES particular. Com o diagnóstico Retinose Pigmentar, possui apenas a visão central, ela não consegue ver os campos periféricos, por exemplo o chão, o teto, as laterais, visualiza apenas o que está no centro, no momento não utiliza a bengala para se locomover. Realiza leitura em tinta desde que a fonte esteja aumentada, faz as avaliações do curso em tinta com fonte ampliada.

Participante-pesquisadora 4: tem 23 anos e prestará vestibular para o curso de Pedagogia da UEPG (Universidade Estadual de Ponta Grossa). Possui baixa visão (entre 10 e $15 \%$ ) no olho direito, e cegueira total no esquerdo. Atualmente passou por um transplante no olho esquerdo e está em período pós-operatório, utiliza a bengala para se locomover, faz uso do braile com dificuldade. Realiza leituras através de leitores de tela ou através da escuta de leitura oral feita por outras pessoas. Já prestou dois vestibulares em IES pública, mas não conseguiu ingressar no curso pretendido.

Participante-pesquisador 5: tem 46 anos, cursa o oitavo período de Direito na UEPG. Com cegueira adquirida, utiliza a bengala para se locomover, não faz uso do braile. Realiza leituras através de leitores de tela ou através da escuta de leitura oral feita por outras pessoas, realiza as avaliações oralmente com leitores e transcritores.

Participante-pesquisadora 6: tem 16 anos, cursa o segundo ano do Ensino Médio em escola pública e participará em 2018 da segunda etapa do PSS (Processo Seletivo Seriado) para ingressar num curso da UEPG, à princípio pretende Administração, mas revela que seu sonho é cursar Psicologia, curso oferecido apenas por IES particulares. Com cegueira congênita, utiliza a bengala para se locomover, faz uso do braile desde a infância. Realiza leituras através de leitores de tela, faz as avaliações oralmente com a presença de um leitor/transcritor.

Participante-pesquisadora 7: tem 22 anos, cursa o sexto período de Direito em IES particular e atualmente trabalha como estagiária voluntária no CEJUSQ (Centro Jurídico de Soluções de Conflitos e Cidadania), atuando como digitadora dos termos dos acordos. Com cegueira adquirida, utiliza a bengala para se locomover, faz uso do braile desde a adolescência. Realiza leituras através de leitores de tela, recebe as avaliações do curso em pen-drive e resolve com o auxílio do computador através de programas de leitura de tela, não precisa do auxílio de monitores, leitores/transcritores. 
Participante-pesquisadora 8: tem 15 anos, cursa o primeiro ano do Ensino Médio e pretende prestar vestibular para o curso de Direito. Com baixa visão, não utiliza bengala para se locomover. Realiza leitura em tinta com fonte ampliada e realiza as avaliações em tinta com fonte ampliada.

Participante-pesquisador 9: tem 32 anos e está concluindo o Ensino Médio através do programa EJA (Educação para Jovens e Adultos), pretende fazer o vestibular para Administração. Com cegueira adquirida, utiliza a bengala para se locomover, não faz uso do braile. Realiza a leitura através de leitores de tela, faz as avaliações oralmente com a presença de um leitor e/ou transcritor.

Explicamos que para este trabalho utilizamos apenas os relatos dos acadêmicos, pois estão diretamente relacionados com o objetivo do artigo, entretanto os depoimentos dos estudantes que pretendem ingressar em cursos de graduação serão contemplados no decorrer da pesquisa de doutorado.

\section{Encarando o presente}

Medrado e Dantas (2014, p. 234) falam da importância da língua(gem) no desenvolvimento das pessoas cegas, as autoras explicam que "o desconhecimento das políticas de inclusão e do universo da pessoa com deficiência pode provocar situações de estresse para o professor e para os alunos" (MEDRADO; DANTAS, 2014, p. 234). Elas reforçam também que um professor que inicia um trabalho com alunos cegos ou com baixa visão precisa conhecer e desenvolver um repertório de saberes; ao mesmo tempo, deve socializar tais conhecimentos com os pares.

Nesse sentido, nós acrescentamos que o professor, ao trabalhar neste contexto, precisa rever seu papel e questionar uma crença central ${ }^{22}$ tão enraizada na sociedade que diz e repete "o professor está na escola para ensinar e o aluno para aprender" (MARTINS, 2016, p. 112). O professor deve despir-se desta crença e inverter o papel, ele precisa perceber-se um aprendiz, entender que a realidade e a experiência do aluno cego com o aprendizado é substancialmente diferente do que se possa imaginar, pois "a cegueira, na criação de uma nova e única forma de personalidade, traz à vida forças novas; ela muda as tendências normais de funcionamento; ela, criativa e organicamente, refaz e transforma a mente de uma pessoa" (VIGOSTSKI, 1994, p. 2). Mesmo prevendo ou planejando uma forma de trabalhar, de compartilhar um conteúdo, a prática e o

\footnotetext{
22 A expressão "crenças centrais" é utilizada por Rokeach (1968 apud BARCELOS, 2007), de acordo com os autores essas crenças são as mais difíceis de sofrerem mudanças ou de se alterarem.
} 
contato com um aluno cego demonstrarão que muitas vezes o planejamento terá que ser descartado e refeito ${ }^{23}$. Então, o professor precisa estar disposto a conversar com esse estudante, verificar os diferentes pontos de vistas dele e dispor-se a trilhar um novo caminho - no qual surgem um professor/aprendiz e um aluno/ensinante ${ }^{24}$ - para juntos encontrarem uma forma possível de ensino-aprendizagem.

A seguir apresentamos algumas análises de experiências relatadas pelos estudantes no universo acadêmico. Algumas declarações são muito encorajadoras e refletem o bom desempenho, a persistência e um pouco da rotina desses estudantes dentro da universidade; outras, porém, mostram o quanto estes acadêmicos são invisibilizados, o quando são esquecidos, deixados de lado ou tratados com indiferença. Para organizar nossa análise, dividiremos em duas seções: a primeira aborda o sonho de ingressar numa universidade e a segunda apresenta algumas experiências da realidade universitária vivenciadas pelos acadêmicos.

\section{O sonho de ser universitário}

Lembremos as palavras de Maher:

A modernidade nos fornecia conceitos teóricos acabados, inertes, encapsulados e, por isso mesmo, confortáveis, seguros: deles derivávamos "certezas" que nos ofereciam sabores de Verdade. A pósmodernidade nos força a sair desses casulos teóricos de modo a enfrentar a turbulência provocada por comportamentos sociolinguísticos fluídos e a acomodar o inesperado e o movimento que a compreensão do mundo atual exige (MAHER, 2007, p. 91, grifo da autora).

Assim, a inclusão de pessoas cegas nos ambientes acadêmicos pode ser vista como uma dessas turbulências, e nós, os envolvidos, precisamos sair dos casulos teóricos e questionarmos as certezas/verdades que na maioria das situações foram e ainda são impostas por ideologias hegemônicas. De acordo com McCarty (2011), as ideologias linguísticas são, na maioria das vezes, pressupostos tácitos, assumidos por estados de língua(gem), formas, usuários e usos que, em virtude de sua naturalização de

\footnotetext{
${ }^{23}$ Para conhecer um exemplo dessa prática apontamos a leitura do artigo "Para não dizer que não falei 'das cores': ressignificando o fazer na aula de língua inglesa" (MEDRADO; DANTAS, 2014), no texto as autoras descrevem aulas em que professores tentam ensinar as cores em inglês para alunos cegos, mas precisam rever e modificar o planejamento a todo momento.

${ }^{24}$ Cf. FREIRE, P. Carta de Paulo Freire aos professores. Ensinar, aprender: leitura do mundo, leitura da palavra. Estudos Avançados, São Paulo, v.15, n.42, 2001, p. 259-268, o autor utiliza os termos aprendente e ensinante.
} 
'senso comum', contribuem para a desigualdade linguística e social. Afinal, as ideologias linguísticas

não são apenas sobre linguagem. Em vez disso, elas visualizam e encenam os laços da linguagem com a identidade, a estética, a moralidade e a epistemologia. Através dessas ligações, elas sustentam não apenas a forma e o uso linguístico, mas também a própria noção de pessoa e do grupo $\operatorname{social}^{25}$ (WOOLARD, 1998, p. 3).

Obviamente as reflexões apontadas aqui não conseguirão dar conta de explicar a complexa função e relação da língua(gem) com a formação individual e social de cada pessoa, esse não é nosso objetivo. No entanto, pretendemos apontar o quanto algumas ideologias linguísticas orientam e reproduzem pensamentos hegemônicos que, nós, falantes, professores e estudiosos da língua acabamos repetindo (in)conscientemente sem questionarmos os reais valores e crenças transmitidos aos nossos alunos, sejam eles cegos ou videntes.

Nos relatos a seguir percebemos a influência positiva e negativa de pessoas que convivem com os universitários cegos/baixa visão e mesmo tendo conhecimento da realidade, podem incentivá-los ou desmotivá-los através de afirmações tidas como comuns, mas que farão toda a diferença na vida de cada um desses estudantes.

No primeiro encontro de grupo focal os universitários revelaram alguns de seus anseios e a influência de certas pessoas na decisão do curso superior. Vejamos o que disse a Participante-pesquisadora 3:

Participante-pesquisadora 3 - Eu decidi fazer Radiologia... Meu oftalmologista disse que não iria valer à pena, pois eu não poderia trabalhar com isso. ( $1^{0}$. Encontro de grupo focal, 19/04/18)

Questionamos até que ponto o oftalmologista deveria fazer esta afirmação. Por um lado, ele desmotivou a jovem ao dizer que não poderia trabalhar no campo da Radiologia; mas, por outro lado, a estudante revelou que por causa dessa afirmação ela decidiu ir até a Faculdade para conhecer os demais cursos e quando ouviu as explicações e teve contato com a rotina do curso de Produção Publicitária, se apaixonou. No momento em que redigimos o artigo, ela estava cursando o segundo

\footnotetext{
${ }^{25}$ Do original: ideologies of language are not about language alone. Rather, they envision and enact ties of language to identity, to aesthetics, to morality, and to epistemology. Through such linkages, they underpin not only linguistic form and use but also the very notion of the person and the social group. (WOOLARD, 1998, p.3)
} 
período da graduação e não se percebe estudando ou trabalhando em outro ramo; ela comenta que se encontrou no curso.

A Participante-pesquisadora 1 também relatou o quanto as pessoas próximas a ela afirmavam que não adiantava fazer o curso de Educação Física:

Participante-pesquisadora 1 - Um professor de Atletismo disse 'por que você não faz Educação Física?, eu já tinha pensado em fazer, mas outras pessoas falavam 'como você vai fazer Educação Física se você não enxerga'?(1 ${ }^{0}$. Encontro de grupo focal, 19/04/18)

A estudante prestou vestibular para Agronomia na UEPG e ficou oitava na lista de espera, mas no dia que seu nome saiu no edital para realizar a matrícula ela já estava praticando Atletismo e isso a influenciou muito na escolha do curso superior. $\mathrm{O}$ apoio do professor também foi fundamental:

Participante-pesquisadora 1 - Entrei no Atletismo e pensei em fazer Educação Física... O professor me incentivou a fazer o que as pessoas acham que não sou capaz. E ele me incentivou a fazer Educação Física, me ajudou na matrícula e a conseguir a bolsa. (Entrevista individual, 16/10/18)

Além do apoio dos profissionais envolvidos com a educação inclusiva, os familiares e amigos podem influenciar positivamente na escolha do curso:

Participante-pesquisador 2 - Minha família sempre me incentivou, meus pais, meus amigos e professores. Eu sempre gostei muito de me comunicar... Quando eu tinha seis, sete anos eu já sonhava em fazer Jornalismo. (Entrevista individual, 05/11/18)

Na fala do estudante conhecemos um menino, que aos seis anos de idade já queria ser jornalista e hoje, aos 21 anos, realiza-se no curso escolhido. O jovem relatou também que chegou a fazer um teste vocacional que apresentava como cursos possíveis: Psicologia, Filosofia, Sociologia e Direito, mas não aparecia Jornalismo. Mesmo assim, com apoio dos amigos, professores e familiares, ele decidiu entrar no curso e está no sexto período.

\section{A realidade acadêmica}

Nos relatos acima, percebemos o desejo e as decisões dos universitários diante da possibilidade de cursar uma graduação. Encontraram muitos obstáculos nas escolas regulares e nos vestibulares, na universidade as dificuldades serão muito parecidas, pois 
eles encontrarão pessoas dispostas a aprender com eles, mas precisarão estar preparados para lidar com a indiferença, a desatenção, o esquecimento e a hostilidade.

Por isso, nós, professores devemos ter em mente o quanto o sujeito, sua história de vida, sua língua(gem $)^{26}$ e todo o contexto a sua volta, influenciam no seu desenvolvimento como cidadão, como pessoa, como profissional, entre outras identidades que possa vir a assumir. E, para que a inclusão de alunos cegos/baixa visão aconteça realmente nos ambientes acadêmicos e eles não sejam eliminados pelos processos avaliativos, precisamos compreender a cegueira, não como uma deficiência, mas como uma habilidade a mais (VIGOSTSKI, 1994). Quando nós, profissionais da educação, nos abrimos para o aprendizado, nos aproximamos e enxergamos neles habilidades que não possuímos, a aprendizagem é possível e de maneira natural. Nesse sentido, foi muito interessante ouvir relatos que demonstram a sensibilidade e disponibilidade de alguns professores:

Participante-pesquisadora 1 - Eu não entendia como funcionava o jogo de vôlei, aí o professor pegou um caderno para representar o campo, o espiral era a rede, alguns copinhos de café para representavam os jogadores... Quando ele fez isso, eu entendi. Ficou muito fácil. ( $3^{0}$. Encontro de grupo focal, 21/06/18)

Ao perceber que a aluna não entendia como acontecia o jogo de vôlei, o professor universitário improvisou e, utilizando-se de objetos disponíveis, tentou explicar de maneira concreta. A estudante, ao colocar as mãos e perceber a disposição dos elementos do jogo (campo-caderno, rede-espiral, jogadores-copos) teve uma visão sensorial e compreendeu como o esporte funcionava. A mesma jovem contou sobre a experiência de uma prova de cálculo, ela teve de ensinar a monitora a utilizar a calculadora científica para depois fazerem a prova. Tal acontecimento deixou o nervosismo em segundo plano:

Participante-pesquisadora 1 - Ontem teve uma prova de cálculo, era cálculo a prova inteira... eu tinha que usar a calculadora científica, a professora autorizou o uso do celular, mas no dia da prova eu pedi emprestada uma calculadora científica para verificar os resultados. A moça que me auxiliou na prova disse que não sabia mexer na calculadora científica e eu tive que ensiná-la, eu fazia as operações no celular e a moça fazia na calculadora, a primeira questão

\footnotetext{
${ }^{26}$ Utilizamos a expressão "sua língua(gem)" pois entendemos que a língua/linguagem possui uma profunda relação com a formação individual e social de cada indivíduo. Não podemos observar os alunos cegos/baixa visão apenas como falantes da língua portuguesa, pois há particularidades na aquisição e utilização da língua: o uso do braile e as constantes descrições orais são exemplos que citamos anteriormente.
} 
demorou uma meia hora, mas depois foi tranquilo. Ela foi muito querida... Era uma prova que eu estava com medo, mas com toda a situação eu fiquei confiante, eu acredito que fui muito bem! $\left(3^{0}\right.$. Encontro de grupo focal, 21/06/18)

No quarto encontro questionamos a Participante-pesquisadora 1 sobre o desempenho na prova de cálculos e ela disse ter ido bem, apesar de todo o nervosismo.

Vemos também que alguns estudantes se sentem mais nervosos diante de alguma avaliação, mas na maioria das vezes o processo é natural para eles. O Participantepesquisador 2 relata como faz as avaliações no curso de Jornalismo e que não precisa do auxílio de monitores ou ledores. Ele próprio, os professores e a turma já estão bem acostumados com a situação:

Participante-pesquisador 2 - É sempre bem tranquilo fazer as provas para mim... Tem as questões objetivas e as discursivas. O professor entrega a prova no pen-drive e eu faço no computador com um programa que faz a leitura. Eu já estou acostumado e os colegas também. $\left(3^{0}\right.$. Encontro de grupo focal, 21/06/18)

No entanto, estas atitudes que deveriam ser as mais comuns, uma vez que o ambiente universitário prevê pluralidade e diversidade em todos os sentidos, não são as que geralmente acontecem. Em vários relatos, percebemos que em inúmeros momentos eles são esquecidos, são tratados com indiferença e com desconfiança. Vejamos o que diz o graduando em Direito, o Participante-pesquisador 5. Ele foi até a universidade para realizar a prova, como os demais alunos, entretanto, ficou no corredor esperando e parece que ninguém percebeu a sua presença:

Participante-pesquisador 5 - Cheguei para fazer a prova e fiquei sentado no banco do corredor, como sempre fiz. Eu ouvi quando a professora passou e entrou na sala... fiquei esperando do lado de fora um tempão. Depois, como ninguém veio falar comigo, eu fui até a sala, ouvi uns alunos conversando e perguntei sobre a professora. Eles falaram que todos já haviam terminado a prova e a professora já tinha ido embora... Foram todos embora e me esqueceram lá no corredor, será que eles não me viram? ( $3^{0}$. Encontro de grupo focal, 21/06/18)

Outros estudantes comentaram que é muito constrangedor quando alguma pessoa se aproxima e em vez de direcionar a pergunta a eles, cegos, fazem a pergunta para seus acompanhantes. Comentaram que isso os chateia pois eles conseguem ouvir a pessoa, perceber que ela se aproxima. Outra questão apontada por eles é a desconfiança dos colegas de turma, em vários relatos explicaram que muitos desconfiam que os leitores/monitores ajudam nas avaliações dos cursos: 
REVISTA X, Curitiba, volume 14, n.4,p. 300-321, 2019

Participante-pesquisador 5 - Quando eu tiro nota baixa ninguém fala nada, mas quando eu tiro nota alta dizem que a monitora me ajudou. $\left(3^{\circ}\right.$. Encontro de grupo focal, 21/06/18)

Além da desconfiança, os universitários contaram que várias vezes, em dias de avaliação, o professor chega na sala com as provas em papel, mas acaba esquecendo a prova no pen-drive. Geralmente a situação é resolvida, mas precisam esperar a prova enquanto os demais colegas já estão fazendo. Isso causa certo desconforto:

Participante-pesquisadora 7 - Às vezes acontece de algum professor esquecer a prova no pen-drive, aí a turma começa a prova e eu começo depois. ( $3^{\circ}$. Encontro de grupo focal, 21/06/18)

Entendemos que é neste contexto de complexidade que devemos discutir a questão da inclusão de alunos cegos ou com baixa visão nos ambientes acadêmicos. $\mathrm{O}$ sucesso de cada um desse alunos dependerá de inúmeros fatores, entretanto, é essencial um corpo de professores comprometidos com a qualidade da educação. Concordamos com Fontana (2014, p. 58) quando afirma que "não há pessoas com deficiências. O que há, na verdade, é uma sociedade deficiente. As pessoas são diferentes. Simplesmente isso. Há seres humanos de todos os tamanhos, cores e sabores”. E nós complementamos, ao invés de colocarmos a venda nos demais alunos, para que percebam como os estudantes cegos não enxergam, deveríamos convidar todos os membros das turmas a prestarem mais atenção nos sons, nos movimentos, nos cheiros, nas mais variadas percepções que nós não conseguimos ver, mas os alunos cegos compreendem perfeitamente.

\section{REFERÊNCIAS}

AZEVEDO, J. A. de. O Instituto dos Meninos Cegos de Paris: sua historia, e seu methodo de ensino por J. Guadet. Rio de Janeiro: Typographia de F. de Paula Brito. 1851.

BÍGLIA, L. M. A inclusão por seus colaboradores. In: MOHR, A. M. et al. Pensando a Inclusão. Curitiba: Ed. UTFPR, 2012. p.49-60.

BRASIL. Lei no4.024, de 20 de dezembro de 1961. Fixa as Diretrizes e Bases da Educação Nacional. Diário Oficial da União, Brasília, DF. Disponível em: http://www.planalto.gov.br/ccivil_03/LEIS/L4024.htm. Acesso em 10 ago. 2018.

Lei no 5.692, de 11 de agosto de 1971. Fixa as Diretrizes e Bases para o ensino de $1{ }^{\circ}$. e $2 \circ$. graus, e dá outras providências. Diário Oficial da União, Brasília, DF. 
REVISTA X, Curitiba, volume 14, n.4,p. 300-321, 2019

Disponível em: http://www.planalto.gov.br/ccivil_03/Leis/L5692.htm. Acesso em 10 ago. 2018.

[Constituição (1988)]. Constituição da República Federativa do Brasil. Brasília, DF: Presidência da República, [2016]. Disponível em: http://www.planalto.gov.br/ccivil_03/Constituicao/Constituicao.htm. Acesso em: 16 ago. 2018.

Lei no 7.853, de 24 de outubro de 1989. Dispõe sobre o apoio às pessoas portadoras de deficiência, sua integração social, sobre a Coordenadoria Nacional para Integração da Pessoa Portadora de Deficiência. Diário Oficial da União, Brasília, DF. Disponível em: http://www.planalto.gov.br/ccivil_03/Leis/L7853.htm. Acesso em: 30 jun. 2018.

Decreto-lei no. 6.094, de 24 de abril de 2007. Estabelece as Diretrizes do Compromisso de Todos pela Educação. Diário Oficial da União, Brasília, DF. Disponível em: http://www.planalto.gov.br/ccivil_03/_ato20072010/2007/decreto/d6094.htm. Acesso em: 30 jun. 2018.

CARDOSO, C. M. Tolerância e seus limites: um olhar latino-americano sobre diversidade e desigualdade. São Paulo: UNESP, 2003.

CÉSAR, A. L.; CAVALCANTI, M. C. Do singular para o multifacetado: o conceito de língua como caleidoscópio. In: CAVALCANTI, M. C. \& BORTONI-RICARDO, S. M. (Orgs.) Transculturalidade, linguagem e educação. Campinas-SP: Mercado de Letras, 2007, p. 45-66.

CONSELHO NACIONAL DE EDUCAÇÃO. Resolução no. 1, de 18 de fevereiro de 2002.Estabelece as Diretrizes Curriculares Nacionais para a Formação de Professores da Educação Básica. Diário Oficial da União. Brasília, DF, 18 fev. 2002. Disponível em: http://portal.mec.gov.br/cne/arquivos/pdf/rcp01_02.pdf. Acesso em: 30 jun. 2018.

DANTAS, R. A proposta educacional inclusiva: aspectos da legislação. In: MEDRADO, B. P. (Org.) Deficiência visual e ensino de línguas estrangeiras: políticas, formação e ações inclusivas. Campinas: Pontes Editora, 2014. p.33-56.

FABRÍCIO, B. F. Linguística aplicada como espaço de "desaprendizagem": redescrições em curso. In: MOITA LOPES, L. P. (Org.) Por uma linguística aplicada indisciplinar. São Paulo: Parábola Editorial, 2006, p.45-65.

FONTANA, M. V. L. Novas tecnologias e novos olhares: um caminho para a inclusão de pessoas com deficiência visual. In: MEDRADO, B. P.(Org.) Deficiência visual e ensino de línguas estrangeiras: políticas, formação e ações inclusivas. Campinas: Pontes Editora, 2014. p.57-76

FRANCO, J. R.; DIAS, T. R. da S. A pessoa cega no processo histórico: um breve percurso. Revista Benjamin Constant, Edição 30, abril de 2005. Disponível em: http://www.ibc.gov.br/?catid=4\&itemid=10028. Acesso em: 07 jun. 2018. 
MAGALHÃES, R. de C. B. P. Currículo e inclusão de alunos com deficiência no ensino superior: reflexões sobre a docência universitária. In: MELO, F. R. L. V. (Org.) Inclusão no Ensino Superior: docência e necessidades educacionais especiais. Natal: EDUFRN, 2013. p.45-57.

MAHER, T. M. Do casulo ao movimento: a suspensão das certezas na educação bilíngue e intercultural. CAVALCANTI, M. C. \& BORTONI-RICARDO, S. M. (Orgs.) Transculturalidade, linguagem e educação. Campinas-SP: Mercado de Letras, 2007. p.67-94.

MARTINS, S. de F. C. Avaliação em língua portuguesa no ensino fundamental: crenças existentes e resistentes.2016. 167 f. Dissertação (Mestrado em Linguagem, Identidade e Subjetividade) - Setor de Ciências Humanas, Letras e Artes, Universidade Estadual de Ponta Grossa, Ponta Grossa, 2016.

McCARTY, T. L. (Org.) Ethnography and language policy. New York: Routledge, 2011.

MEDRADO, B. P. (Org.) Deficiência visual e ensino de línguas estrangeiras: políticas, formação e ações inclusivas. Campinas: Pontes Editora, 2014.

MEDRADO, B. P; DANTAS, R. Para não dizer que não falei "das cores": ressignificando o fazer na aula de língua inglesa. In: MEDRADO, B. P. (Org.) Deficiência visual e ensino de línguas estrangeiras: políticas, formação e ações inclusivas. Campinas: Pontes Editora, 2014. p.233-250.

MECLOY, E. P. Psicologia de la ceguera. Madrid: Editorial Fragua, 1974.

OLMO, F. J. C. del. Tradução, Língua e Identidade em poetas occitanos e catalães do século XIX, elementos para uma tradução entre línguas românicas. 2014. 436 f. Tese (Doutorado em Estudos da Tradução) - Setor de Linguística, Letras e Artes, Universidade Federal de Santa Catarina, Florianópolis, 2014.

PESSOTTI, I. Deficiência mental: da superstição à ciência. São Paulo: Editora da Universidade de São Paulo, 1984.

RAJAGOPALAN, K. Por uma linguística crítica: linguagem, identidade e a questão ética. São Paulo: Parábola Editorial, 2003.

SASSAKI, R. K. Entrevista. Revista Integração, (20), p. 08-10. Brasília: SEESP/MEC, 1998.

UNESCO. Declaração de Salamanca e linha de ação sobre necessidades educativas especiais. Espanha: UNESCO, 1994. Disponível em: http://portal.mec.gov.br/seesp/arquivos/pdf/salamanca.pdf. Acesso em: 17 jul. 2018.

VIGOTSKI, L. S. A criança cega. Tradução de Adjuto de Eudes Fabri. Versão original “The Blind Child”, 1934. Versão concluída em 1994.

WOOLARD, K. A. Introduction: Language Ideology as a Field of Inquiry. In: SCHIEFFELIN, B.B.; WOOLARD, K.A.; KROSRITY, P.V. Language Ideologies: Practice and Theory. New York: Oxford University Press, 1998. p.3-50. 